\title{
FORMAÇÃO CONTINUADA DE PROFESSORES QUE ATUAM COM O ENSINO DA ARTE NA ESCOLA DE EDUCAÇÃO BÁSICA, INSTITUIÇÕES PÚBLICAS DE ENSINO SUPERIOR, EXTENSÃO UNIVERSITÁRIA E O TERCEIRO SETOR.
}

\author{
Continued Formation of Teachers that teach Art at the Basic Education, Publics \\ Institutions of Superior Teaching, University Extension and the Third Sector.
}

\author{
Professora Me. Sandra Francisco ${ }^{10}$
}

\begin{abstract}
RESUMO
Este artigo é parte de uma dissertação de mestrado onde se relata e analisa a formação continuada de professores que atuam com o Ensino de Arte na Escola de Educação Básica em Belém e região metropolitana. Relata a contribuição do Terceiro Setor na formação continuada do professor. Parte do pressuposto que a melhor qualidade da Formação Continuada do Professor de Arte não se garante apenas por meio da utilização de significativo material didático - pedagógico, mas sim, com os processos de mediação desenvolvidos na constituição do conhecimento em arte.
\end{abstract}

Palavras Chave: Formação continuada de professores; parceria; ensino da Arte.

\begin{abstract}
This paper is part of a Master's degree text where it relates and analyses how the continued formation of teachers at the basic education that teach art in the city of Belem in the state of Para. Accounts for the contribution of the Third Sector in the continued formation of teachers and it assumes that the best quality of the continued formation of teachers of art it is not guareented only through the use of significant educational materials, but with the process of mediation developed in the structure of the knowledge in art.
\end{abstract}

Keywords: Continued Formation of teachers; partnership; Art teaching.

\section{RESUMEN}

Este articulo es parte de una dissertacion de maestria que relata y hace un analisis de la formacion continuada de profesores de la escuela basica que ensenan arte en Belem, en el estado del Para. Relata la contribuicion del Tercero Sector para la formacion continuada del profesor, parte de la idea de que la mejor formacion continuada del profesor de arte no se garante apenas por el uso de significativo material didactico-pedagogico, pero si, por los processos de mediacion desenvolvidos en la construcción del conocimiento en arte.

10 Sandra Suely dos Santos Francisco. Mestre. Secretaria Estadual de Educação do Pará e Secretaria Municipal de Educação de Belém, cedida para atuar na Universidade Federal do Pará. Av. 25 de Setembro, 2019. Apto 401-A. Belém, PA. 66093-000. (91)99889665. sandrafrancisco@yahoo.com.br. 
Palabras-clave: Formación continuada de profesores; parceria; enzenanza del Arte.

\section{Introdução}

A necessidade de atuar para atender as demandas sociais tem se ampliado significativamente a cada dia. É necessário criar novas frentes de trabalho que possibilitem o atendimento dessas demandas, pois sabemos que o Estado não oferece políticas e serviços satisfatórios para suprir as necessidades da sociedade brasileira. Assim, surgem novas frentes para estes atendimentos e essas incluindo as instituições do Terceiro Setor - apresentam-se com propostas inovadoras, administração mais ágil que a das instituições públicas e, cada vez mais, tornam-se parceiras do Estado no atendimento das exigências sociais.

A participação dos atores sociais é de grande importância no processo de constituição das parcerias. Essa participação propicia a construção de propostas de intervenção a partir de uma realidade conhecida e vivida, objetivando soluções aos problemas do cotidiano. Nesse sentido, as instituições do terceiro setor que atuam na área educacional, possibilitam essa articulação, pois "na prática, o terceiro setor parece estar caminhando para uma articulação conjunta, em termos de frente de trabalho" (GOHN, 2001, p. 83). E nessa questão, já que "o Estado não consegue mais penetrar nas microesferas da sociedade" (ibidem, p. 83), essas instituições apresentam solução à problemática.

Para atender a demanda de professores de Arte da extensa região metropolitana de Belém, composta por 06 (seis) municípios e dois distritos totalizando 2.162.977 habitantes $^{11}$, estes professores necessitam de uma formação continuada de qualidade e assim se faz necessária a ampliação de parcerias entre instituições do Terceiro Setor e instituições educacionais públicas preocupadas em oferecer tal modalidade de formação. Tais parcerias, a exemplo da existente entre o Instituto Arte na Escola e a Universidade Federal do Pará (UFPA), estão em consonância com o que pressupõe Gohn (2001, p. 73), quando diz que: "a nova forma supõe novas regras de contrato social que envolva parcerias entre o público estatal com o chamado público não estatal, ou seja, com o terceiro setor".

http://www.ibge.gov.br/home/estatistica/populacao/estimativa2006/POP 2006 DOU.pdf e http://www.citybrazil.com.br/pa/regioes/belem/index.htm 
A partir dessa parceria está implantado na Universidade Federal do Pará o Programa Arte na Escola - UFPA/Belém ou PAE - UFPA/Belém. O Programa faz parte da Rede Arte na Escola, uma Rede constituída por universidades e instituições culturais que tem por objetivo atuar para a melhoria do Ensino de Arte no Brasil. Tem o Instituto Arte na Escola como seu mantenedor, que por sua vez recebe incentivos da Fundação lochpe ${ }^{12}$. Esse instituto pertence à categoria chamada Terceiro Setor, cujo conceito é ainda carente de rigor teórico, conforme nos diz Montaño (2005).

No Terceiro Setor, a iniciativa da esfera privada surge para atender ao interesse público e sua atuação vem crescendo significativamente no Brasil, principalmente na área social, na qual ações desenvolvidas por organizações da sociedade civil assumem questões da sociedade dando resposta às demandas sociais a partir de valores de solidariedade local, auto-ajuda e ajuda mútua (MONTAÑO, 2005). Esse setor se caracteriza pela atuação na área social e se propõe a contribuir para a formação e fortalecimento do comportamento do cidadão e da cultura democrática, trazendo desenvolvimento e mudanças, propiciando a construção da democracia e a promoção da cidadania (TORO, 1997), segundo seu próprio conceito ideológico dominante, que o define como setor nem público, nem privado.

O PAE - UFPA/Belém funciona em um espaço cedido pela UFPA no prédio do Atelier de Artes do Instituto de Ciências da Arte. Faz parte da parceria, a cessão de instalações físicas e a concessão de bolsas de Extensão aos alunos que participam do desenvolvimento de ações. Essas bolsas são disponibilizadas pelo Programa de Bolsas da Pró-Reitoria de Extensão da UFPA. Mantém também, professores coordenadores, sendo 01 (um) cedido da Secretaria Estadual de Educação do Pará e Secretaria Municipal de Educação de Belém. É de se ressaltar que as ações do Pólo são referências no Estado do Pará, sobretudo no que diz respeito à Formação Continuada dos Professores de Arte da Educação Básica.

As ações de Formação Continuada propostas pelo Programa Arte na Escola Pólo Belém - fortalecem a proposta de Extensão da UFPA. Pois, ela é promovida em parceria com instituições de educação e apoio à cultura com o intuito de

\footnotetext{
${ }^{12}$ Organização do Terceiro Setor vinculada ao Grupo Empresarial lochpe.
} 
produzir conhecimentos e qualificar recursos humanos, por meio de ações de ensino, pesquisa e extensão, na perspectiva de buscar a transformação do ensino da Arte na educação básica do estado do Pará.

Como diz Marques (2003), a formação continuada deve ser constituída como obra de um empenho coletivo dos educadores, tendo como base programas que possam ser, ao mesmo tempo, participativos, orgânico-sistêmicos e continuados, além de exigir uma equipe dedicada ao trabalho docente, solidária, integrada e adequada às particularidades dos alunos. Tais parcerias, no entanto, só darão retorno social se houver o engajamento efetivo das instâncias envolvidas e vontade política, essencial para a mobilização da sociedade.

Nesse contexto, espera-se que a universidade se reconheça enquanto espaço de construção de conhecimentos, atue na realidade social e busque parcerias que propiciem a socialização dos saberes constituídos. Nisto, inclui-se trabalhos parceiros com os professores dos sistemas de ensino, de modo a possibilitar que a escola cumpra o seu compromisso social, pois é "somente na docência em sala de aula, e por causa dela, [que] a escola assume e cumpre seu compromisso social de instância da aprendizagem sistemática requerida pelos demais tempo-lugares da vida dos homens" (MARQUES, 1995, p. 145).

Assim, concordamos que cabe, então, à universidade, ampliar seus espaços de ação, também no que diz respeito à socialização das práticas educativas. E para que tal ampliação se concretize é necessária a parceria constante com as secretarias de educação na intenção de informar e formar o professor. Trata-se de planejar ações conjuntas que incentivem o professor a participar dos cursos de formação continuada, tais como as de ajuda financeira e liberação de carga horária de trabalho. Nossa experiência profissional, com atuação no PAE - UFPA/Belém permite afirmar que a indisponibilidade financeira e o número de horas das exaustivas jornadas de trabalho representam os fatores que impedem a participação dos professores nos cursos programados.

A universidade pública é um espaço de construção de conhecimentos que deveria estar sempre a serviço da comunidade a qual pertence. Ao nos depararmos com a problemática da formação continuada de professores, sentimos a necessidade de buscar soluções à questão, no sentido de auxiliar o professor a refletir sua prática, em tempos e espaços remunerados para isso, contando com o respaldo de políticas públicas para tais fins. Desta forma, é legado aos professores 
o repensar da prática, a avaliação e a busca de fundamentação teórica, suporte essencial para o desenvolvimento de sua prática social significativa. Sabemos que a formação continuada do professor visa à competência profissional, de modo a Ihe oferecer instrumentos que possam auxiliar em seu trabalho de intervenção na sociedade e na busca de soluções aos problemas do cotidiano.

$\mathrm{Na}$ análise das entrevistas realizadas com professores que participam e com os que não participam da formação continuada do PAE - UFPA/Belém, para nossa dissertação de Mestrado, e observando a proposta apresentada por Mazzeu (1998), refletimos acerca de sua aplicabilidade no desenvolvimento das ações articuladas pela parceria que constitui o Programa. Essa parceria é evidenciada no compromisso com a formação continuada de professores de Arte da região metropolitana de Belém e numa materialização desta proposta que parte da prática social, passa pela problematização, pela instrumentalização, catarse e retorna à prática social.

A proposta de Mazzeu (1998) é fundamentada na prática pedagógica e possui referenciais que regem a pedagogia histórico-crítica sistematizada por Saviani. Mazzeu afirma que: "Para conseguir que os alunos se apropriem do saber escolar de modo a se tornarem autônomos e críticos, o professor precisa estar, ele próprio, apropriando-se desse saber e tornando-se cada vez mais autônomo e crítico" (MAZZEU, 1998, p. 61).

Baseado em Saviani, a proposta histórico-social de Mazzeu, orienta metodologicamente uma seqüência de trabalho, tendo como foco a Formação Continuada de Professores. Ele nos diz que a prática social, não deve ser confundida com a experiência de cada indivíduo. Partir da prática social na formação de professores implica não só o conhecimento de seus saberes, de suas memórias, de seus saberes práticos, como também a ruptura com a forma de pensamento e ação, próprios do cotidiano. Daí termos que "são essas relações contraditórias que estão no ponto de partida da formação de professores, uma vez que essa formação ocorre nessa prática social e não apenas no momento em que o professor recebe algum tipo de curso" (MAZZEU, 1998, p.64).

A prática social é sempre uma contextualização do conteúdo e um momento de conscientização do que ocorre na sociedade em relação ao tópico a ser trabalhado. É o momento de retorno, de transformação das formas de pensar e agir em torno dos conteúdos escolares. Sobre a problematização, "segundo 
Saviani, a necessidade de refletir filosoficamente evidencia-se quando o ser humano se encontra diante de uma situação problemática" (SAVIANI apud MAZZEU, 1998, p. 65). Na problematização, o professor identifica as necessidades percebidas no cotidiano, a partir das próprias experiências de vida, e passa a refletir sobre a questão no sentido da superação do problema (MAZZEU, 1998).

No que diz respeito à instrumentalização, Mazzeu (1998) afirma que ela ocorre na apropriação dos instrumentos e signos elaborados e acumulados pelo homem e, ao mesmo tempo, na criação de novos instrumentos e signos. $O$ professor elabora seus próprios instrumentos e discursos, assimilando a produção de outros e se envolvendo afetivamente com esses instrumentos, de modo a utilizá-los em benefício do desenvolvimento da humanidade e de cada indivíduo.

Quanto à catarse, tem a sua conceituação como a

[...] constituição de uma espécie de 'segunda natureza', isto é, são formas de pensar e agir produzidas histórica e socialmente, que se incorporam de tal maneira na estrutura psíquica do indivíduo que as utiliza que aparecem como formas naturais, mas que na verdade resultam de um longo processo educativo (SAVIANI apud MAZZEU, 1998, p.70).

Na catarse, a operação fundamental é a síntese do cotidiano e do científico, do teórico e do prático a que o educando chegou. É o momento que o pensamento chega a uma conclusão, sendo este o ponto culminante do processo educativo (GASPARIN, 2005). Com a catarse, o estudante, "constitui para si uma nova visão da realidade" (ibidem, p. 129). É o momento do encontro e da integração mais clara e consciente da teoria com a prática na nova realidade, quando o aluno percebe que a realidade antes conhecida como "natural" agora é histórica, pois foi produzida pelo homem em determinado tempo e lugar, atendendo a intenções políticas implícitas e explicitas, como também aos interesses e necessidades socioeconômicas.

Percorridos os "passos" acima, se retoma a prática social dentro da contextualização fechando os ciclos da formação continuada do professor e sua práxis, o que conforme o modelo proposto acontece pela "criação de necessidades novas e como colocação de novos temas objeto de [...] reflexão [...]" (MAZZEU, 1998, p. 65). Daí tem-se que, "a prática social referida no ponto de partida (primeiro passo) e no ponto de chegada (quinto passo) é e não é a mesma" 
(SAVIANI apud MAZZEU, 1998, p. 71), pois, sendo a mesma no sentido de que a transformação das formas de pensar e agir em face dos conteúdos escolares já não o é, em razão de que professor e alunos transformaram-se no transcurso do processo. Transformações que se refletem nas demais instâncias da sociedade, tanto no âmbito das produções reflexivas, como nas produções da existência material (MAZZEU, 1998).

Assim, se vislumbra a possibilidade do Programa Arte na Escola estar em consonância com a referida proposta no que tange à formação continuada do professor de Arte. Neste sentido, foi possível perceber, por meio das respostas dos professores às perguntas formuladas nas entrevistas, que a formação continuada é de grande importância, pois possibilita a reflexão da prática, a socialização de experiências, bem como a construção de novas propostas para o ensino de Arte.

Levando em consideração a análise do conteúdo das entrevistas, percebemos que o professor, mesmo com a posse do material de qualidade disponibilizado pelo Instituto Arte na Escola para ser utilizado em sala de aula, necessita de conhecimentos da arte e da educação, para melhor articular a construção de conhecimentos significativos de seus alunos. Além disso, é necessário que o professor assuma compromisso político com os alunos na medida em que remete sua prática social educativa ao resgate da cidadania, utilizando-se de mecanismos e meios mediadores do ato político pedagógico.

É necessário ainda, e de grande importância, que a UFPA, por meio do PAE UFPA/Belém, busque ampliar as parcerias com a Secretaria de Educação do Estado do Pará, com a Secretaria Municipal de Educação de Belém e as secretarias dos demais municípios da região metropolitana. Essas parcerias poderão facilitar o acesso dos professores às informações educativas e ações propostas pelo Programa, além de permitir a freqüência eficaz e compatível com as necessidades profissionais.

No tocante à aferição do atendimento às necessidades dos educadores com os materiais disponibilizados pelo Terceiro Setor, pelo PAE - UFPA/Belém foi possível visualizar a importância da Midiateca, para a construção de práticas educacionais significativas. Foi detectado que esses materiais atendem as necessidades dos professores de arte que atuam na região metropolitana de Belém, quando utilizados no contexto da formação continuada, bem como no contexto da atividade pedagógica. Em relação ao acesso a esses materiais, os 
entrevistados apontaram a dificuldade que encontram em pesquisar esse acervo do Programa, que está no Campus Universidade Federal do Pará, em Belém, cuja localização dificulta o acesso constante e rápido.

A não participação de algumas professoras às ações de formação continuada do PAE - UFPA/Belém deve-se principalmente ao fato do desconhecimento de tal parceria e projetos. Alegaram também, o problema do difícil acesso ao Pólo, em relação à localização das escolas em que atuam. Isso trouxe à tona a questão da desarticulação das instituições e redes de ensino ao promover a socialização e a formação continuada de professores de arte a partir das propostas originadas nas ações do PAE - UFPA/Belém, o que evidencia a necessidade de maior divulgação das ações do Pólo de forma descentralizada, fazendo chegar tais informações diretamente ao público alvo. A título de sugestão, cada Secretaria Municipal de Educação dos municípios da região metropolitana de Belém poderia ter, em sua dependência, um Pólo disseminador, com pessoal responsável pelas ações programadas.

Para atender às necessidades dos professores, contemplando horários e atividades, seria de grande valia que os eventos de formação continuada do PAE UFPA/Belém fossem realizados em diferentes períodos, com divulgação adequada de forma a sensibilizar os docentes e com conteúdos que contemplem as reais necessidades pedagógicas dos professores e suas respectivas escolas. Assim, a situação poderia ser outra, no que diz respeito à participação dos docentes. Urge que as instituições responsáveis pela educação estejam envolvidas, em parceria, nos processos de formação continuada. É premente o engajamento dos gestores dos diversos níveis da Educação Básica nesse processo formativo a fim de que possam ampliar seus olhares sobre o ensino de Arte, bem como valorizar e viabilizar parcerias necessárias à concretização da formação continuada do professor de Arte.

Pode-se observar nas narrativas das entrevistas com os professores, participantes e não participantes da formação continuada proporcionada pelo PAE - UFPA/Belém, que há diferença na atuação e consideração dos mesmos quanto as ações formativas. Certamente por conta dos momentos de reflexão desenvolvidos em tais cursos, os professores que deles participaram demonstraram desenvolver práticas pedagógicas fundamentadas em teorias e focalizar a construção de conhecimento de modo articulado com determinadas 
concepções. Também apontaram para a necessidade e importância do uso dos materiais de suporte pedagógico oferecidos pelo Pólo. De acordo com o dizer desses mesmos professores, tais materiais, embora considerados de significativa qualidade, estão atrelados à questão da mediação, o que evidencia a constante preocupação que o professor necessita ter para manter-se atualizado a fim de ampliar seus recursos e estratégias na constituição do conhecimento em arte. Os cursos de formação continuada oferecidos pelo PAE-UFPA/Belém objetivam enfatizar a mediação do professor na utilização dos materiais disponibilizados, evidenciando que, em si mesmos, eles pouco significam. O enriquecimento de seus efeitos na aprendizagem está na qualidade dos processos de mediação e não em sua materialidade.

A articulação entre os materiais de suporte pedagógico oferecido pelo Pólo e a mediação do professor é pouco percebida entre os professores entrevistados, não participantes dos cursos de formação continuada. A título de ilustração, podemos citar o caso de um professor que se recusou a participar da entrevista, dando a perceber que sentia-se despreparado para responder às questões relativas à sua formação continuada.

Finalizando este trabalho, podemos afirmar que o pressuposto da pesquisa de nossa dissertação de mestrado, o qual ressalta que a melhor qualidade da Formação Continuada do Professor de Arte não se garante por meio da utilização de significativo material didático-pedagógico, mas por processos de mediação desenvolvidos na constituição do conhecimento em arte, são evidenciados nas vozes da maioria dos professores entrevistados. Isto deveria se tornar, a nosso ver, ponto de atenção e reflexão no desdobramento das ações de um trabalho de parceria entre as instituições públicas ou privadas com o Terceiro Setor.

Visando à melhor qualidade do processo de aprendizagem em Arte, o olhar do educador apóia-se na materialidade dos suportes pedagógicos como instrumentos para explorar as múltiplas possibilidades de mediar a constituição do conhecimento. Tais possibilidades se constroem, sobretudo, nas oportunidades de trocas e vivências coletivas que os cursos de formação continuada podem oferecer aos profissionais da educação. Nossa esperança é que as narrativas registradas e analisadas na pesquisa realizada possam desencadear ações efetivas de melhor qualidade, constituídas na perspectiva da parceria e capazes de transformar a 
realidade dos processos de mediação e aprendizagem, promovendo mudanças nos significados dos cursos de formação continuada dos educadores ligados à área da Arte.

\section{REFERÊNCIAS}

FRANCISCO, Sandra. A formação continuada de professores de arte da região metropolitana de Belém na perspectiva da parceria. 2007. Dissertação (Mestrado em Educação). Universidade de Uberaba, Minas Gerais. 2007

GOHN, Maria da Glória. Educação não formal e cultura política: impactos sobre o associativismo do terceiro setor. São Paulo: Cortez, 2001.

MARQUES, Mário Osório. Escola , aprendizagem e docência: imaginário social e intencionalidade política. In: VEIGA, IIma Passos A. (Org.). Projeto político pedagógico da escola: uma construção possível. 4. ed. (Coleção Magistério: Formação e Trabalho Pedagógico). Campinas: Papirus, 1995.

MARQUES, Mário Osório. Formação do profissional da educação. 4. Unijuí: Ijuí, 2003.

MAZZEU, Francisco José Carvalho. Uma proposta metodológica para a formação continuada de professores na perspectiva histórico social. Cadernos CEDES, Campinas, ano 19, n. 44, abr. 1998.

MONTAÑO, Carlos. Terceiro setor e questão social: critica ao padrão emergente de intervenção social. São Paulo: Cortez, 2005.

SAVIANI, Demerval. Pedagogia Histórico-crítica: primeiras aproximações. 8. ed. rev. e amp. Campinas: Autores Associados, 2003.

SAVIANI, Dermeval. Educação: do senso comum à consciência filosófica. 13. ed. Campinas: Autores Associados, 2000.

SAVIANI, Demerval. Pedagogia Histórico-crítica: primeiras aproximações. 6. ed. Campinas: Autores Associados, 1997.

SAVIANI, Demerval. Educação: do senso comum à consciência filosófica. 5. ed. São Paulo. Autores Associados, 1985.

TORO, José Bernardo. O papel do terceiro setor em sociedades de baixa participação (Quatro teses para discussão). In: IOCHPE, Evelyn Berg . $3^{\circ}$ setor: desenvolvimento social sustentado. Rio de Janeiro: Paz e Terra. 1997.

Texto recebido em 30 jun. 2008 Texto aprovado em 10 set. 2008. 